\title{
Avaliação da segurança do trabalho em obras de manutenção de edificações verticais
}

\author{
Esdras Campos de Mélo Filho a* Emilia Rahnemay Kohlman Rabbanib, \\ Béda Barkokébas Júnior ${ }^{c}$ \\ a*esan@oi.com.br, UPE, Brasil \\ bemilialsht@upe.poli.br, UPE, Brasil \\ cbedalsht@upe.poli.br, UPE, Brasil
}

\begin{abstract}
Resumo
A manutenção de edificações é um tema cuja importância tem crescido no setor da construção civil, superando gradualmente a cultura de que o processo de construção encerra-se na entrega do produto. Esta pesquisa visa avaliar a situação de algumas obras de manutenção de edificações verticais na cidade de Recife, no que diz respeito ao cumprimento das normas de segurança e saúde do trabalho - SST, como também identificar as principais falhas de projeto dessas edificações que geram potencialmente riscos à manutenção. 0 estudo consistiu na visita e análise de oito edificações em serviços de manutenção, entre outubro de 2008 e fevereiro de 2009, aplicando-se uma lista de verificação, com base nas normas e leis de SST vigentes. Observaram-se, na pesquisa, falhas nos projetos arquitetônicos das edificações, irregularidades nos procedimentos de segurança e falta de conhecimento dos síndicos quanto à contratação e à fiscalização da empresa de manutenção. Constatou-se que as fases de planejamento e projeto de uma edificação são vitais para garantia da segurança do trabalhador na fase de manutenção. Visualizou-se a necessidade de desenvolver futuros estudos a fim de estabelecer diretrizes de segurança para o desenvolvimento de projetos das edificações que antecipem as necessidades de manutenção e a segurança daqueles que realizam esses trabalhos.
\end{abstract}

Palavras-chave

Manutenção de edificações. Segurança e saúde do trabalho. Construção civil. Gestão de SST. Gestão de projetos.

\section{Introdução}

A manutenção de edificações é uma etapa do processo construtivo à qual uma especial importância precisa ser dada, por ser essencial na preservação das características de desempenho para o qual a edificação foi inicialmente projetada. De acordo com Mélo Filho (2009), muitas normas de construção apresentam deficiências, assim como a maioria dos profissionais quando focam somente as três atividades centrais do processo construtivo (projeto, materiais e construção), ignorando as fases de planejamento e manutenção.

De acordo com a Organização Internacional do Trabalho - OIT, o setor da construção civil apresenta mundialmente uma tendência de aumento das atividades de reformas e manutenção de edifícios. Estas atividades representam, atualmente, porcentagem significativa da movimentação do setor, totalizando quase 50\% em algumas economias mais desenvolvidas, caso do Japão (INTERNATIONAL..., 2004).

Entretanto, observa-se, no setor, a falta da análise das condições de segurança na fase da concepção do projeto da obra, contribuindo para elaboração de projetos deficientes, com inúmeras situações de risco que poderiam ser evitadas nas fases de execução e da manutenção (MÉLO FILHO; KOHLMAN RABBANI; BARKOKÉBAS JUNIOR, 2008).

Rwamamara et al. (2010), ao entrevistar projetistas suecos, revelaram a necessidade de se considerar e de se criarem instrumentos de avaliação da segurança do trabalho na etapa de planejamento do projeto das edificações. Entretanto, os projetistas expressaram não ser comum a cobrança desses quesitos pelas construtoras. Os autores citam vários trabalhos 
(SPIELHOLZ; CHAVEZ, 2006) que justificam o investimento na etapa de planejamento, tendo em vista os benefícios econômicos relacionados ao aumento da produtividade, devido à eliminação de retrabalho e à redução das incertezas pela falta de comunicação adequada das partes envolvidas.

De acordo com Cooke et al. (2008), para melhorar os índices de segurança na indústria da construção, arquitetos e engenheiros projetistas deveriam administrar uma avaliação de risco completa de cada projeto elaborado.

Sendo assim, esta pesquisa visa avaliar a situação de algumas obras de manutenção no que diz respeito ao cumprimento das normas de SST, levantando as principais falhas de projeto que apresentaram potencial de risco e identificando oportunidades de melhoria na fase de elaboração dos projetos e na administração dos serviços de manutenção.

\section{Referencial teórico}

\subsection{Atividades de manutenção em edificações verticais}

\subsubsection{Conceito de manutenção}

De acordo com o dicionário Aurélio, manutenção são as "Medidas necessárias para a conservação ou a permanência de alguma coisa ou de uma situação". Convergindo com esse conceito, a NBR 5674 (ASSOCIAÇÃO..., 1999) define manutenção como conjunto de atividades a realizar para conservar ou recuperar a capacidade funcional da edificação e de suas partes constituintes, a fim de atender às necessidades de segurança dos seus usuários.

De acordo com Marcelli (2007), na engenharia civil a manutenção deve ser um conjunto de medidas necessárias e indispensáveis para garantir o bom estado de funcionamento, conservação e segurança dos equipamentos/elementos e instalações de uma edificação, de qualquer tipo ou grandeza, resultando num conjunto de ações preventivas e corretivas cuja finalidade é preservar o cumprimento satisfatório das funções para as quais a edificação e seus componentes foram projetados, de forma a garantir a vida útil desejada do imóvel.

A Figura 1 mostra a influência da manutenção no prolongamento da vida útil da edificação. Analisando-a, percebe-se que, quando são executadas manutenções periódicas para recuperar o nível de desempenho de um determinado material, consegue-se prolongar o tempo de vida útil deste, devido ao prolongamento do tempo para que se atinja o nível mínimo de desempenho aceitável.

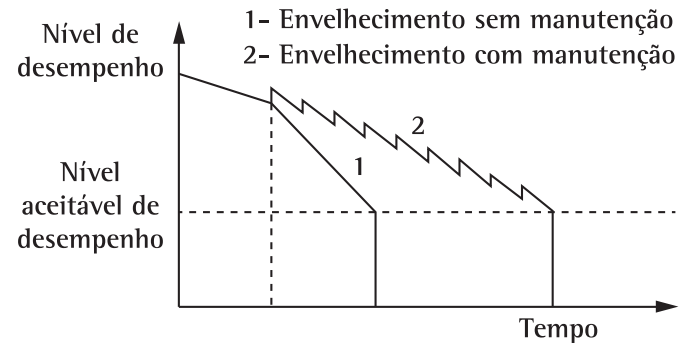

Figura 1. Influência da manutenção na durabilidade dos materiais. Fonte: Marcelli (2007).

Deve-se entender também que a manutenção não pode ser considerada um sucesso quando se aplicam técnicas caras e obtém-se baixo retorno de investimento (EDWARDS; HOLT; HARRIS, 1998). Além de instrumento valioso para a obtenção de informações preciosas que subsidiam o desenvolvimento de novos projetos, o programa de manutenção deve-se mostrar vantajoso, financeiramente, a médio e a longo prazo.

Atualmente, a aplicabilidade do programa de manutenção esbarra num paradigma do setor da construção: a grande rejeição, por parte dos responsáveis pelos imóveis, ao desembolso previamente programado para a manutenção preventiva, considerado um gasto desnecessário. No entanto, arriscar-se a ter de realizar uma obra corretiva pode custar muito mais que a manutenção preventiva (NARAYA, 1998). Na verdade, esse raciocínio equivale ao daquele indivíduo que, por acreditar que está economizando o valor do prêmio a ser pago, não faz seguro, correndo o risco de perder tudo (MARCELLI, 2007).

\subsubsection{Métodos de manutenção}

As atividades de intervenção pós-obra na construção civil podem ser divididas em atividades de manutenção e atividades de melhoria, abrangendo objetivos bem distintos. De acordo com Xenos (1998), as atividades de manutenção visam manter suas condições originais de operação e de desempenho através do restabelecimento de eventuais deteriorações destas condições. As atividades de melhoria, por sua vez, são aquelas que visam melhorar as condições originais de operação, de desempenho e de confiabilidade da edificação, mediante alterações do projeto original.

Com foco nas atividades de manutenção, Gomide (2006) faz uma distinção de conceitos, classificando a manutenção como preventiva, corretiva, preditiva e detectiva.

A manutenção preventiva atua antecipadamente à ocorrência do problema, para que não haja a reparação. Pode ser definida também como um 
conjunto de atividades que visam evitar problemas nos componentes ou equipamentos que possam vir a afetar a sua performance. Já a manutenção corretiva busca reparação, caracterizada por serviços planejados ou não, a fim de corrigir falhas. De acordo com Helene (1992 apud GOMIDE, 2006), esse é considerado o método mais caro de gerência de manutenção.

A manutenção preditiva visa o estudo de sistemas e de equipamentos, com análises de seus comportamentos e usos, a fim de predizer e apontar eventuais anomalias, além de direcionar e implementar os procedimentos de manutenção preventiva (GOMIDE, 2006). Por sua vez, a manutenção detectiva objetiva apurar a causa dos problemas e falhas ocorridos para a sua análise, auxiliando os planos de manutenção. Esta é também chamada de engenharia de manutenção ou de manutenção proativa.

\subsubsection{Procedimentos de manutenção para as edificações}

Salienta-se que as atividades de manutenção estabelecidas demandam serviços especializados de engenharia que devem ser dirigidos por profissionais legalmente habilitados, sendo este o próximo enfoque.

A manutenção dos edifícios engloba todas as atividades necessárias para o perfeito e contínuo funcionamento dos seus equipamentos e instalações. Com esse raciocínio, Martins (2004) concorda que a manutenção dos edifícios compreende todas as atividades que se realizam nos seus equipamentos, elementos, componentes ou instalações com a finalidade de assegurar-lhes condições satisfatórias de segurança, habitabilidade e eficiência, para o cumprimento das funções para as quais foram fabricados ou construídos.

Assegurar a manutenção dessas condições implica observar os quatro requisitos básicos da edificação citados pela NBR 5674 (ASSOCIAÇÃO..., 1999): funcionalidade, segurança, higiene e conforto.
Bezerra (2000) descreve essas características, fazendo distinção das atividades realizadas periodicamente que demandam serviços especializados. Para esses serviços, o autor identifica as diversas atividades de manutenção, correlacionando com as áreas de atuação das engenharias. 0 foco desse estudo irá ater-se aos serviços especializados de engenharia civil, destacados no Quadro 1.

\subsubsection{Gestão e coordenação de projeto: fase importante para redução de custos e análise de segurança das atividades de manutenção}

Melhado (2005) e Souza (2003) afirmam que, nos últimos anos, muitas construtoras passaram a se interessar pela racionalização de métodos construtivos e pela implementação de sistemas de gestão da qualidade. Nessa busca, percebe-se que o processo do projeto vem-se destacando como elo fundamental da cadeia produtiva da construção civil. 0 projeto, além de ser um instrumento de decisão sobre as características do produto, influi diretamente nos resultados econômicos dos empreendimentos e interfere na sua eficiência.

0 investimento no projeto, em prazo e custo, deve ser valorizado, porque permite desenvolver um projeto mais amplo, com maior nível de detalhamento, possibilitando também viabilizar soluções mais eficazes, de forma a garantir facilidades e segurança às operações de manutenção da edificação.

Nesse sentido, aconselha-se que, na concepção do projeto, haja auditoria de segurança do trabalho, analisando as condições em que o projeto será executado e, posteriormente, as condições em que a manutenção da edificação será realizada. Com isso, a avaliação e o controle dos riscos podem ser contemplados na fase de concepção e planejamento da edificação, subsidiando ferramentas eficientes que garantam a SST, posteriormente, nas atividades de manutenção.

Quadro 1. Áreas de atuação das engenharias nos edifícios.

\begin{tabular}{|c|c|c|c|c|}
\hline Administração & Tipo de manutenção & Equipe & Especialidade & Atividades \\
\hline \multirow{7}{*}{$\begin{array}{c}\text { Empresa } \\
\text { administradora } \\
\text { de condomínio }\end{array}$} & $\begin{array}{l}\text { Manutenção } \\
\text { permanente }\end{array}$ & $\begin{array}{l}\text { Equipe } \\
\text { própria }\end{array}$ & Serviços rotineiros & Limpeza, vigilância, portaria, manutenção básica, serviços de urgência \\
\hline & \multirow{6}{*}{$\begin{array}{l}\text { Manutenção } \\
\text { periódica }\end{array}$} & \multirow{6}{*}{ Parceiros } & $\begin{array}{l}\text { Engenharia } \\
\text { civil }\end{array}$ & $\begin{array}{l}\text { Instalações elétricas, instalações hidráulicas, estrutura de concreto } \\
\text { armado, manutenção de revestimentos e serviços gerais de construção }\end{array}$ \\
\hline & & & E. mecânica & Elevadores, bombas \\
\hline & & & E. eletroeletrônica & Subestação, transformadores e geradores \\
\hline & & & Química & Qualidade da água \\
\hline & & & Arquitetura & Reformas, decorações \\
\hline & & & lnformática & Computadores, TVs \\
\hline
\end{tabular}

Fonte: adaptado de Bezerra (2000). 


\subsection{Segurança e saúde do trabalho nas atividades de manutenção}

Analisando-se a causa dos acidentes na indústria da construção em Pernambuco no ano de 2005, de acordo com o Sindicato da Indústria da Construção Civil do Estado de Pernambuco (2007), 27 acidentes provêm de queda de andaimes, e 19, de choques elétricos, com o que constata-se o potencial de risco das atividades de manutenção em fachadas e instalações elétricas.

Acompanhando tais resultados, em uma análise dos acidentes fatais de outubro de 2001 a dezembro de 2006, Holmes (2007) quantificou 132 acidentes de trabalho fatais só em Pernambuco, dos quais 41 ocorreram na indústria da construção (31\%). Afirma ainda que desses registros fatais em Pernambuco, 28 provêm de quedas e 20, de choques elétricos.

Esse elevado nível de acidentes em instalações elétricas pode ser explicado por um estudo recente desenvolvido por Kohlman Rabbani et al. (2008a). Os autores avaliaram os sistemas de proteção das instalações elétricas nas residências de Pernambuco, revelando percentuais que chamam atenção para o descaso relacionado às instalações elétricas residenciais: mais de 50\% dos quadros de distribuição apresentam exposição a partes vivas e 65\% das instalações pesquisadas não possuíam nenhum tipo de equipotencialização de massas. Problemas esses que agravam o risco para as atividades de manutenções.

Em outra pesquisa, Almeida Filho et al. (2007) destaca como principal motivo dos registros de acidentes fatais na região metropolitana do Recife as atividades de manutenção ou construção predial, demonstrando assim a relevância da avaliação na segurança em operações de manutenção em edificações. De acordo ainda com Panpalon, Lenci Filho e Vicente (2008), as principais causas de mortes de trabalhadores se devem a acidentes envolvendo quedas de pessoas e de materiais, e muitos desses acidentes fatais têm acontecido nas atividades de manutenção e de conservação de fachadas de edifícios.

Conclui-se que, pelo elevado potencial de risco de acidentes, as atividades de manutenção em instalações elétricas e em fachadas necessitam de maior atenção na análise dos riscos e seu controle para garantia da segurança do trabalhador nessas operações.

\subsection{Legislação de SST para atividades de manutenção}

Considerando as atividades de manutenção periódicas relacionadas à especialidade da engenharia civil especificadas no Quadro 1, relacionam-se, a seguir, as principais normas que devem ser observadas de acordo com a legislação brasileira de SST:

1. Normas regulamentadoras NR18 (norma específica para as empresas de construção), NR6 (Equipamentos de proteção individual - EPI), NR5 (Comissão Interna de Prevenção de Acidentes - CIPA) e NR4 (que especifica o dimensionamento dos Serviços Especializados em Segurança e Medicina do Trabalho - SESMT) (BRASIL, 2011) são fundamentais por estabelecerem as diretrizes de segurança (e.g. medidas de proteção coletiva e individual e os responsáveis pela implantação destas nas obras) para as atividades de manutenção em fachadas e estruturas de concreto armado;

2. NR10 (BRASIL, 2011), RTP 5 (VIANA et al., 2007) e NBR5410 (ASSOCIAÇÃO..., 2004) relacionadas à segurança nas atividades de manutenção em instalações elétricas, de baixa e alta tensão;

3. NR33 (BRASIL, 2011) que dispõe sobre segurança em espaços confinados e NBR 14.787 (ASSOCIAÇÃ̃O..., 2001) para segurança nas atividades em instalações hidráulicas, específicas à manutenção de caixas d'água;

4. NR15 (BRASIL, 2011) que dispõe sobre atividades e operações insalubres, utilizada para atividades em instalações de esgoto;

5. NR7 (BRASIL, 2011) que trata do Programa de Prevenção de Riscos Ambientais - PPRA e NR9 (BRASIL, 2011) que trata do Programa de Controle Médico e de Saúde Ocupacional - PCMSO, cuja elaboração e implementação são obrigatórias para todos os empregadores e instituições que admitam trabalhadores como empregados, inclusive as que fazem trabalhos de manutenção.

É importante destacar que os programas de segurança PPRA e PCMSO, juntamente com o Programa de Condições e Meio Ambiente de Trabalho na Indústria da Construção - PCMAT (programa específico para as empresas de construção que tenham mais de 20 funcionários e que está detalhado na NR18) especificam as diretrizes para o planejamento do trabalho seguro, visando à integridade do trabalhador e de seu ambiente. Esses programas, quando adequadamente elaborados e utilizados, são instrumentos eficazes para o controle da ocorrência de riscos ambientais e da promoção e preservação da saúde dos trabalhadores.

\section{Método de pesquisa}

Levantaram-se bibliografias sobre procedimentos de segurança em obras de manutenção em edificações verticais, limitando-se a área de atuação da engenharia civil: manutenção elétrica em baixa tensão; manutenção em instalações hidráulicas (água fria, caixas d'água e rede de esgoto); manutenção de revestimentos em fachadas e manutenção em estruturas de concreto 
armado. Com base nesse referencial foi desenvolvido um estudo de campo para avaliar as condições de SST em obras de manutenção de edificações de múltiplos andares na cidade de Recife, PE, visando avaliar a situação de algumas obras de manutenção no que diz respeito ao cumprimento das normas, como também identificar as principais falhas de projeto dessas edificações.

Utilizou-se como ferramenta uma "lista de verificação" (checklist), que foi aplicada em oito obras de manutenção entre os dias 1/10/2008 e 13/2/2009. Escolheu-se pesquisar obras com idade entre 10 e 25 anos de construção, a fim de manter uma certa homogeneidade na amostra e, ao mesmo tempo, permitir a diferenciação entre construções mais novas e mais antigas.

A metodologia adotada na elaboração da lista de verificação toma como base o método de avaliação e controle dos riscos para construção civil no campo da engenharia de segurança do trabalho (BARKOKÉBAS JUNIOR et al., 2004), amplamente utilizado por pesquisadores nas mais diversas áreas relacionadas à SST - e.g. ver os trabalhos de Almeida Filho et al. (2007), Barkokébas Junior et al. (2006), Kohlman Rabbani et al. (2007, 2008a, b), Lago (2008), entre outros. 0 checklist proposto por Barkokébas Junior et al. (2004) baseia-se em classificar e em identificar o risco como conforme ou não conforme, tendo como referencial as legislações vigentes.

Nessa pesquisa, com base nas normas de SST apresentadas no item 2.3 foi elaborado um checklist de três páginas, com 50 itens de análise objetiva, apenas, focando aplicação em obras de manutenção. A parte inicial do checklist pode ser visualizada na Figura 2. Foram adotadas as seguintes condições de resposta: "conforme" (CO), "não conforme" (NC) e "não se aplica” (NE).

\section{Dados da obra \\ - Nome do edifício: \\ - Endereço: $\quad$ № \\ - Bairro: \\ - Ano de término da construção da edificação: \\ - No funcionários: - Eng $^{\circ}$ de obra: \\ - Atividade de manutenção executada na obra: \\ - No total de pavimentos: \\ Inst. elétricas $\square$ Inst. hidráulicas Fachadas $\square$ Estrutura $\square$ Outros serviços \\ Documentações de segurança \\ - Quantidade de acidentes: \\ - cIPA: $\square$ co $\square$ NC $\square$ NE \\ - Quantidade de incidentes: \\ - Documentos na obra \\ $\square$ PPRA \\ Ordens de serviço

PCMAT $\square$ PCMSO
$\square$ Manual de manutenção áreas comun \\ EPI com CA}

Inspeção nas instalações físicas da edificação

a) Inspeção na cobertura

- Possui dispositivos destinados à ancoragem de equipamentos?

- Possui dispositivos destinados à ancoragem de cabos segurança?

- Os dispositivos de ancoragem são independentes?

- Os dispositivos atendem todo o perímetro da edificação?

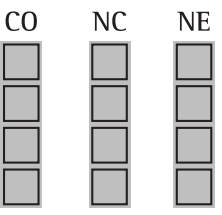

Verificação da NR18 na atividade de manutenção

a) Andaimes suspensos

- Projeto do sistema de fixação e estrutura de apoio dos andaimes

- Andaimes suspensos convenientemente fixados à edificação

- Ancoragem de equipamentos e cabos segurança corretamente fixados

- Cinto de segurança tipo paraquedista, ligado ao trava-quedas de segurança em cabo-guia fixado em estrutura independente da estrutura de fixação e sustentação do andaime suspenso

Figura 2. llustração parcial do checklist desenvolvido. 
0 checklist foi dividido em cinco partes que objetivam obter:

- Dados sobre a empresa de manutenção: Levantaram-se os dados para enquadramento do porte da empresa através da quantidade total de funcionários, além de outros dados como quantidade total de obras, quadro de engenheiros e de técnicos de segurança e a existência de consultores de segurança, entre outras informações iniciais de caracterização da empresa;

- Características da obra: Localização, porte e idade da edificação. Foi identificada também a atividade de manutenção que estava sendo realizada;

- Documentação de SST: Analisou-se a existência das documentações mínimas exigiveis de segurança para execução de obras civis, como PCMAT e PCMSO;

- Inspeção das instalações físicas: Procuraram-se identificar as falhas de projeto nas instalações e as condições de acessibilidade aos seus componentes que, direta ou indiretamente, pudessem interferir e comprometer a SST nas atividades de manutenção. Nessa inspeção foram avaliados o quantitativo e a disposição de pontos de ancoragem na coberta para acesso à fachada, às instalações elétricas (quadros de medição e distribuição) e às instalações hidrossanitárias (caixa d'água, cisternas, sistema de esgoto e de águas pluviais);

- Cumprimento da NR18 na atividade de manutenção: Objetivou avaliar se as empresas cumpriam ou não as normas de SST em suas atividades, com base nas exigências da NR18 aplicáveis a obras de manutenção analisadas. Foram avaliados alguns itens específicos da NR18, a saber, os itens 18.8 (Armações de aço), 18.9 (Estruturas de concreto), 18.15 (Andaimes) e 18.21 (Instalações elétricas), haja vista serem itens diretamente relacionados às atividades de manutenção, foco da pesquisa.

Esse instrumento foi aplicado através de entrevista com o responsável direto pela obra, da empresa de manutenção, que validava as informações, e em alguns casos, na presença do síndico. A aplicação do checklist durava aproximadamente 40 minutos. 0 checklist foi estruturado para ser aplicado em obra de manutenção civil especificada no item 2.1.3, podendo ser aplicado por profissional que tenha noções básicas das normas de segurança do trabalho. Os resultados obtidos a partir de sua aplicação são basicamente qualitativos, sem atribuição de nota.

0 checklist elaborado tem como ponto forte a fácil aplicação, por existirem apenas itens objetivos e a possibilidade de inclusão de notas caso seja necessário. Em contrapartida, possui limitações na análise das instalações físicas da edificação, focando apenas na inspeção dos pontos de ancoragem para acesso à fachada, nas instalações elétricas e hidrossanitárias das edificações.

\section{Resultados}

\subsection{Caracterização das empresas construtoras e obras visitadas}

Para enquadramento do porte das empresas, foi utilizada a definição do Instituto Brasileiro de Geografia e Estatística - IBGE, que classifica o porte das empresas conforme a quantidade de pessoal ocupado. São consideradas microempresas aquelas com até nove pessoas ocupadas, pequenas, aquelas com 10 até 49 pessoas ocupadas, médias, aquelas que ocupam de 50 a 99 pessoas e grandes, aquelas com 100 ou mais pessoas ocupadas.

Nessas condições, das sete empresas construtoras analisadas na cidade de Recife, cinco podem ser consideradas de pequeno porte (P) e duas de médio porte (M). As empresas analisadas possuíam entre $20 \mathrm{e}$ 70 funcionários. No quadro técnico, com exceção da construtora C6, que possuía três engenheiros com especialização em segurança, as demais empresas não possuíam engenheiro de segurança ou consultor e, em alguns casos, apenas um técnico de segurança que vistoriava todas as obras da empresa. Essas informações encontram-se tabuladas no Quadro 2.

Percebe-se que há falta de qualificação e quadro técnico limitado nas empresas visitadas, o que pode talvez ser explicado por serem, na maioria, de pequeno porte. Essa hipótese não pode ser generalizada a partir desta amostra, haja vista o número de empresas pesquisadas não ser representativo do universo de empresas atuantes no setor, mas tal hipótese é respaldada pelo trabalho de Souza (1997).

0 Quadro 3 apresenta um resumo das características das oito obras visitadas, identificadas pelas letras de $\mathrm{A}$ à $\mathrm{H}$, relacionando-as com as empresas visitadas $\mathrm{C} 1$ à $\mathrm{C}$. Vale salientar que as obras $\mathrm{C}$ e $\mathrm{D}$ pertencem à mesma empresa de construção, denominada como C3.

Nota-se que das oito obras visitadas, cinco eram obras de manutenção em fachadas, principalmente de troca de revestimentos, duas realizavam atividades

Quadro 2. Caracterização das empresas construtoras entrevistadas na cidade de Recife.

\begin{tabular}{|c|r|r|r|r|r|r|r|}
\hline \multirow{2}{*}{ Caracterização das construtoras } & \multicolumn{7}{|c|}{ Construtoras } \\
\cline { 2 - 8 } & C1 & C2 & C3 & C4 & C5 & C6 & C7 \\
\hline Quantidade total de obras & 12 & 4 & 7 & 10 & 7 & 13 & 4 \\
\hline Quantidade de obras em Recife & 12 & 2 & 6 & 6 & 7 & 8 & 4 \\
\hline Quantidade total de funcionários & 31 & 20 & 28 & 48 & 65 & 70 & 25 \\
\hline $\begin{array}{c}\text { Porte das empresas } \\
\text { (segundo lBGE) }\end{array}$ & P & P & P & P & M & \multirow{2}{*}{ M } & P \\
\hline Técnico de segurança & 0 & 1 & 0 & 0 & 1 & 1 & 0 \\
\hline Engenheiros de obra & 2 & 1 & 3 & 1 & 2 & \multirow{2}{*}{3} & 1 \\
\hline Engenheiros de segurança & 0 & 0 & 0 & 0 & 0 & & 0 \\
\hline
\end{tabular}


de manutenção em instalações hidráulicas e apenas uma obra realizava recuperação de estrutura de concreto armado. Observa-se ainda que não há uma relação direta entre a quantidade de funcionários da obra e o porte da edificação ou porte da empresa, sendo esta variável regida apenas pela programação de liberação dos recursos por parte do condomínio para execução da obra.

Com relação à contratação dessas empresas, com exceção da obra $\mathrm{D}$ as demais se basearam na proposta de menor preço, com análise subjetiva da experiência profissional da empresa. 0 síndico da obra D contratou uma empresa especializada para fazer um processo licitatório, pelo qual lançou um edital no mercado com especificações técnicas da obra e exigências documentais para classificação das empresas concorrentes.

Uma exigência importante deste caderno de especificações para garantia da SST foi a obrigatoriedade da elaboração, por parte da empresa, do projeto de montagem e instalação das balanças, com descrição não só das especificações e dimensões dos andaimes, mas também com identificação do sistema de ancoragem necessário para acesso a cada ponto da fachada, influenciando positivamente na qualidade e segurança da obra.

Com relação à documentação de SST, verificou-se que nenhuma das edificações visitadas possuía disponíveis no canteiro de obras as documentações de PPRA (para as obras com menos de 20 trabalhadores), PCMAT (para obras com mais de 20 trabalhadores) ou PCMSO. Até a data da visita, as empresas testificaram que não houve registro de acidente de trabalho em suas obras.

\subsection{Análise dos resultados}

\subsubsection{Manutenção elétrica}

Apesar de nenhuma das obras visitadas estarem realizando manutenção de suas instalações elétricas as condições das instalações existentes nas oito obras foram analisadas.
Verificou-se uma grande evolução das condições de segurança nos quadros de medidores nas edificações de construção mais recente. Por exemplo, na obra C, construída há 25 anos, observou-se uma instalação inadequada, com quadro confeccionado em madeira, partes vivas expostas, eletrodutos de aço corroídos, com a agravante da inexistência de sistema de aterramento das carcaças (Figura 3), contrariando o item 5.1.2.2.3.1 da NBR5410. Em contrapartida, na obra $\mathrm{F}$, com tempo de construção de 11 anos, além dos quadros de medidores serem metálicos, há melhor disposição dos cabeamentos, sistema de aterramento no quadro e nas grades metálicas de acesso, além de possibilitar melhor acessibilidade às instalações (Figura 4).

$\mathrm{Na}$ vistoria dos quadros de distribuição, a grande maioria apresentou dificuldade de acesso aos componentes da instalação elétrica, não dispondo de espaço suficiente para eventual substituição de componentes defeituosos, além dos quadros estarem sobrecarregados, sem capacidade para novas instalações. Os condutores também não possuíam padronização de cor, conforme orientação da legislação (neutro: azul; terra: verde-amarela ou verde; fase: qualquer cor, exceto as citadas anteriormente).

Em nenhuma das obras vistoriadas foi encontrada, nos quadros de distribuição, a proteção complementar por dispositivo de proteção à corrente diferencialresidual (dispositivo DR) das tomadas situadas nas áreas externas da edificação (apesar de as edificações não estarem obrigadas a cumprir essa norma devido à sua construção ter sido concluída antes da NBR-5410:2004 entrar em vigor).

Verificou-se, ainda, deficiência no sistema de identificação dos circuitos elétricos nos quadros de distribuição, exigida no item 8.3.2 da NBR5410. Em cada um dos quadros vistoriados foi detectado pelo menos um circuito não identificado no quadro elétrico, geralmente de instalação recente. Nota-se que

Quadro 3. Caracterização das obras entrevistadas na cidade de Recife.

\begin{tabular}{|c|c|c|c|c|c|c|c|c|}
\hline \multirow{3}{*}{ Caracterização das obras } & \multicolumn{8}{|c|}{ Construtoras/obras } \\
\hline & \multirow{2}{*}{$\frac{\mathrm{C} 1}{\mathrm{~A}}$} & \multirow{2}{*}{$\frac{\mathrm{C} 2}{\mathrm{~B}}$} & \multicolumn{2}{|c|}{ C3 } & \multirow{2}{*}{$\frac{C 4}{E}$} & \multirow{2}{*}{$\frac{\mathrm{C} 5}{\mathrm{~F}}$} & \multirow{2}{*}{$\frac{\mathrm{C} 6}{\mathrm{G}}$} & \multirow{2}{*}{$\frac{\mathrm{C} 7}{\mathrm{H}}$} \\
\hline & & & $\mathrm{C}$ & $\mathrm{D}$ & & & & \\
\hline Funcionários diretos & 5 & 4 & 3 & 6 & 7 & 4 & 5 & 4 \\
\hline Funcionários terceirizados & 0 & 0 & 0 & 0 & 0 & 0 & 0 & 0 \\
\hline Total (funcionários) & 5 & 4 & 3 & 6 & 7 & 4 & 5 & 4 \\
\hline Atividade de manutenção executada & MF & MF & $\mathrm{MF}$ & $\mathrm{MF}$ & $\mathrm{MF}$ & $\mathrm{MH}$ & $\mathrm{MC}$ & $\mathrm{MH}$ \\
\hline 1dade da edificação & 23 & 23 & 25 & 20 & 25 & 11 & 24 & 12 \\
\hline $\mathrm{N}^{\circ}$ total de pavimentos tipo & 15 & 15 & 9 & 10 & 8 & 20 & 13 & 8 \\
\hline
\end{tabular}

Legenda: MF - Limpeza, recuperação ou manutenção de fachadas. ME - Manutenção em instalações elétricas. MH - Manutenção em instalações hidráulicas. MC - Manutenção em estruturas de concreto. 
não existe a prática de se atualizar o esquema de identificação dos circuitos elétricos quando da existência de alguma modificação.

\subsubsection{Manutenção de instalações hidrossanitárias}

Na obra C, algumas falhas de projeto que dificultavam os trabalhos de manutenção foram detectadas. 0 acesso às instalações do ramal de descida principal da caixa d'água superior (Figura 5) é bastante limitado, com um vão de apenas $40 \mathrm{~cm}$ de altura para acesso às respectivas instalações. Certamente, com base em análise visual, a baixa iluminação também não atende a legislação, dificultando a visão e podendo levar a acidentes.

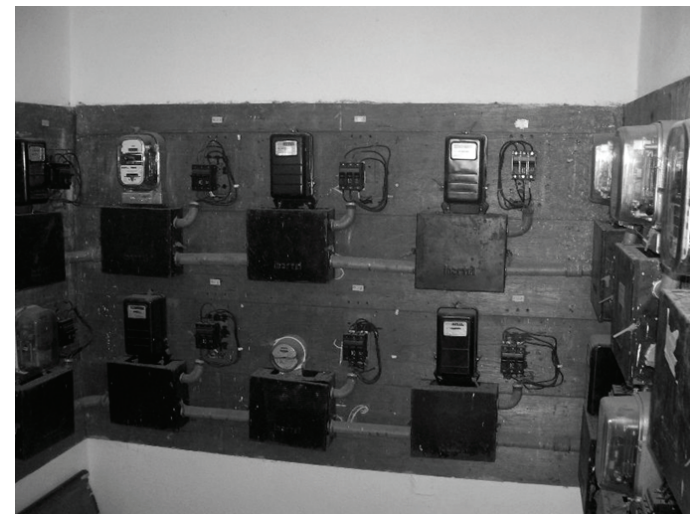

Figura 3. Quadro de medição inadequado - obra C. Fonte: pesquisa de campo.

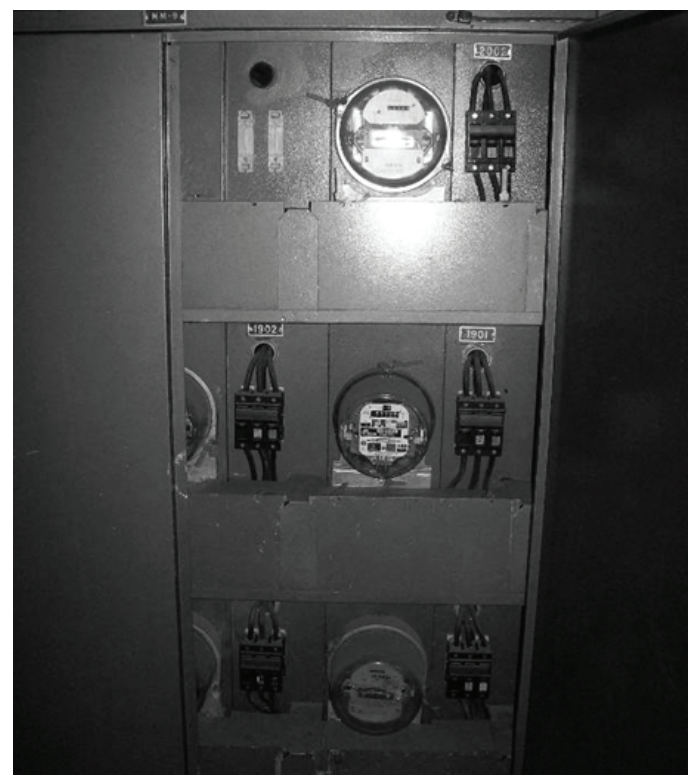

Figura 4. Quadro de medição conforme - obra F. Fonte: pesquisa de campo.
A obra F encontrava-se em atividade de manutenção nas instalações hidráulicas, sendo instalada uma nova tubulação de recalque na fachada da edificação em PVC, devido à tubulação existente ser de cobre e ter estourado devido à corrosão. A construtora fez a instalação da cadeira suspensa na edificação, mas infringindo, gravemente, as normas de segurança (Figura 6).

A sustentação da cadeira suspensa foi feita com corda de filamentos danificados, sem dispositivo de descida com dupla trava de segurança, desrespeitando a alínea b do item 18.15 .51 da NR18. O cinto de segurança tipo paraquedista, além de não ter travaquedas, estava ligado ao único cabo de sustentação do equipamento, com a agravante de a cadeira suspensa ser de fabricação artesanal, infringindo o item 18.15.54 da NR18, que proíbe a improvisação de cadeira suspensa.

$\mathrm{Na}$ obra $\mathrm{H}$, estavam sendo executados serviços de impermeabilização na caixa d'água inferior da edificação. Para realização dos trabalhos, os funcionários não recebiam ordem de serviço com os procedimentos a serem adotados, conforme exigido pelo item 18.20 da NR18.

Percebeu-se que não existia ventilação local de insuflação de ar para o interior do ambiente, além de haver falta de sinalização, informando sobre a realização dos trabalhos, exigidos respectivamente pelas alíneas g e a do item 3.33.2 da NR33 (BRASIL, 2011). Entretanto, houve a preocupação de manter, durante a realização dos serviços, um funcionário na área externa, para inspecionar as áreas adjacentes e possiveis ocorrências no trabalho.

Nas demais obras visitadas, com relação à inspeção das instalações de águas pluviais e de esgoto em geral, verificou-se a dificuldade de acessibilidade às caixas de inspeção por estarem em áreas destinadas a estacionamento de carro.

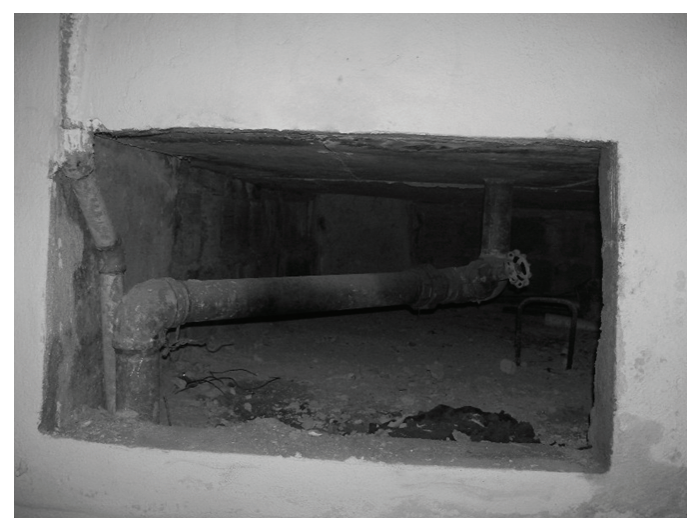

Figura 5. Dificuldade de acesso às instalações hidráulicas do ramal principal - obra C. Fonte: pesquisa de campo. 


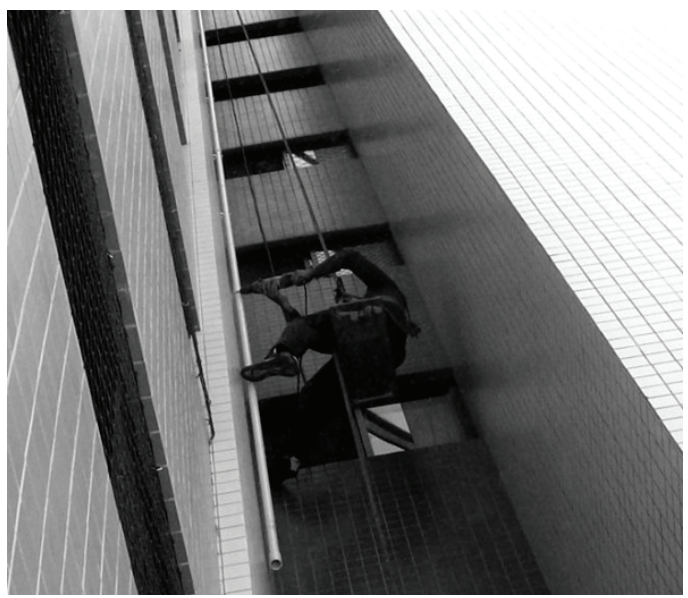

Figura 6. Instalação de tubulação de recalque na fachada - obra F. Fonte: pesquisa de campo.

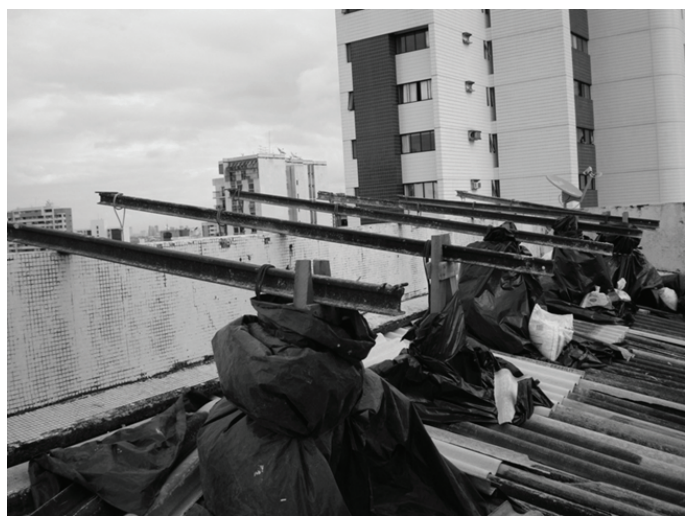

Figura 7. Estrutura de sustentação dos andaimes - obra B. Fonte: pesquisa de campo.

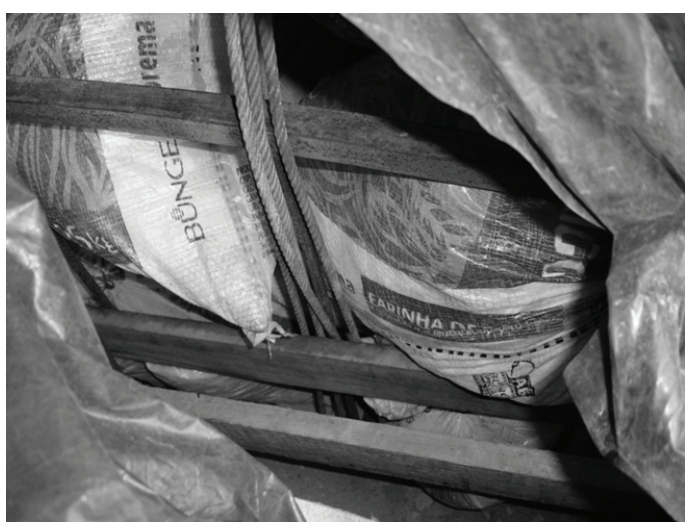

Figura 8. Ancoragem dos cabos de fixação dos cintos em sistema contrapeso - obra B. Fonte: pesquisa de campo.

A obra $F$ foi a única que apresentou todas as caixas de inspeção hermeticamente fechadas e bem localizadas, em áreas estratégicas da edificação, posicionadas em passeios e jardins. Esta edificação era a construção mais nova, de 11 anos, evidenciado-se, portanto, uma evolução nas características técnicas de projeto das instalações hidráulicas que facilita os trabalhos de manutenção em relação às demais edificações.

\subsubsection{Manutenção de revestimentos em fachadas}

Uma das maiores deficiências de projeto observadas na execução das atividades de manutenção das fachadas nas edificações mais antigas foi a falta de pontos de ancoragem em quantidade suficiente na cobertura da edificação. Em todas as obras vistoriadas, apenas a obra $\mathrm{F}$ possuía pontos de ancoragem para equipamentos que atendessem a todo o perímetro da edificação, em contrapartida, não havia disposição para pontos de ancoragem independentes para o cinto de segurança.

Na obra B, como a edificação dispunha apenas de pontos de ancoragem para os equipamentos, a construtora instalou uma gaiola metálica com aproximadamente $200 \mathrm{~kg}$ de brita, para possibilitar fixação independente do cabo para o cinto de segurança (Figuras 7 e 8). Porém, encontra-se em desacordo com a norma que proíbe que o sistema de contrapeso seja em sólido granulado, devendo ser em material de concreto ou aço com seu peso conhecido e marcado de forma indelével em cada peça.

Na obra $A$, a edificação não disponiblizava nenhum ponto de ancoragem na coberta. Por essa razão, a construtora instalou um cabo fixado no pilar do pavimento térreo da fachada posterior, contornando todo o prédio, para servir de ancoragem para os andaimes da edificação (Figuras 9a, b). Todos os cabos de ancoragem de equipamentos e cabos de segurança foram fixados nesse único cabo central, em sistema de contrapeso: uma balança em cada fachada da edificação com os cabos interligados fixados no cabo central. Este sistema de fixação não condiz com o que o item 18.15.32.1 NR18 exige: a sustentação dos andaimes suspensos deve ser fixada em elemento estrutural.

Esse arranjo oferece altíssimo risco, pois se houver rompimento de um dos cabos de sustentação de uma das balanças, o equipamento da outra fachada não terá nenhuma garantia de estabilidade, uma vez que, nessa situação, o cabo central não ficará estático. Há ainda a agravante do cabo de sustentação do cinto de segurança estar fixado no mesmo sistema, tornando-o ainda mais perigoso à execução dos trabalhos e infringindo o item 18.15 .52 da NR18. 
Detectaram-se, nas obras A, C e F, dificuldades de montagem da balança em razão de detalhes construtivos da arquitetura das edificações, que não foram projetados de forma a possibilitar acesso seguro à fachada. Na fachada da obra $\mathrm{A}$, além da dificuldade de instalação do andaime, o cabo de segurança da balança foi instalado friccionando diretamente num detalhe construtivo da edificação, gerando um ponto de desgaste do cabo (Figuras 10a, b).

Levando em consideração ainda os problemas dos projetos arquitetônicos, é válido analisar a obra D. Nesta edificação, antes do início dos trabalhos, a empresa contratada apresentou o projeto de montagem e instalação das balanças, pelo qual descreveu não só as especificações e dimensões dos andaimes, mas também discriminou os pontos de ancoragem para os equipamentos e cabos de fixação do cinto de segurança, apresentados na Figura 11. Entretanto, analisando a edificação, podem-se identificar algumas falhas detectadas nas instalações físicas da edificação que limitaram a elaboração do referido projeto.

Essas falhas detectadas nas instalações físicas da edificação, que consequentemente dificultaram a execução dos trabalhos, poderiam ter sido facilmente corrigidas na etapa de revisão do projeto da edificação, caso tivesse sido feita a análise de SST no projeto inicial de construção da edificação. As principais falhas detectadas encontram-se enumeradas a seguir:
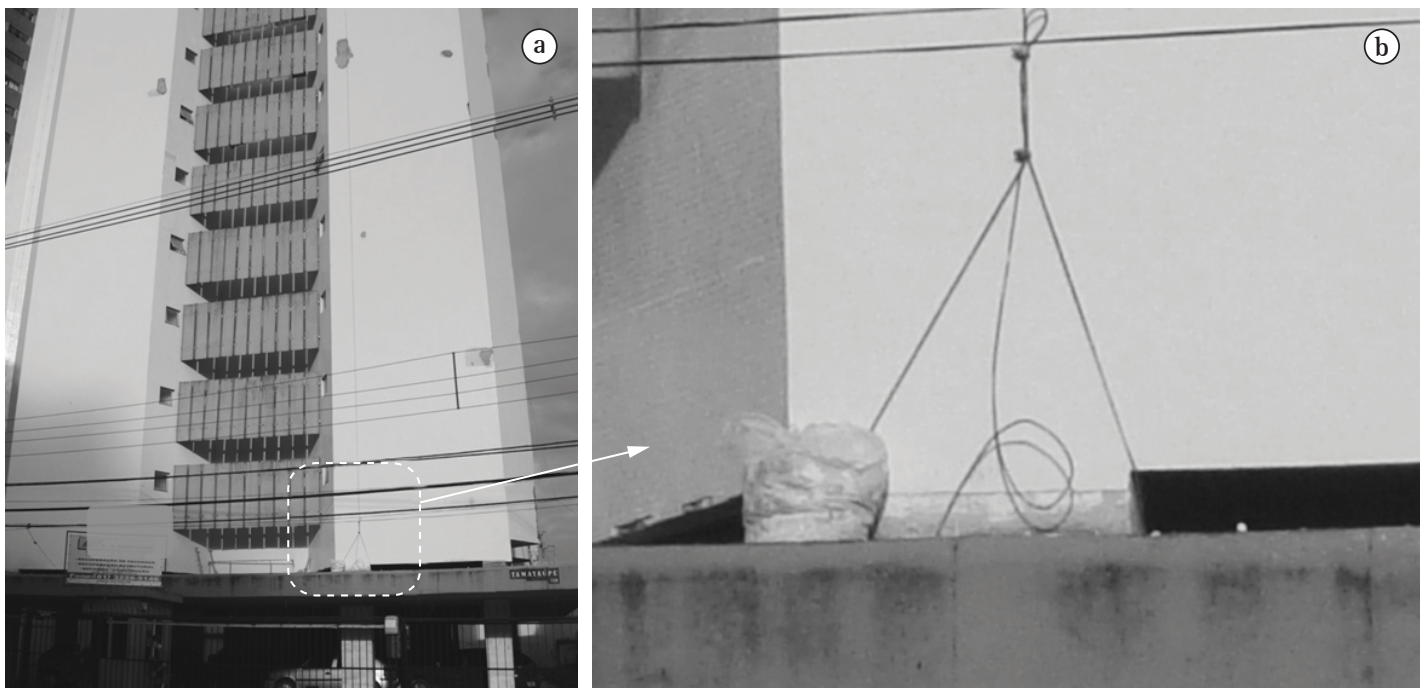

Figura 9. a) Arranjo inadequado do cabo de sustentação da estrutura - obra A. b) Detalhe da fixação inadequada do cabo de segurança - obra A. Fonte: pesquisa de campo.
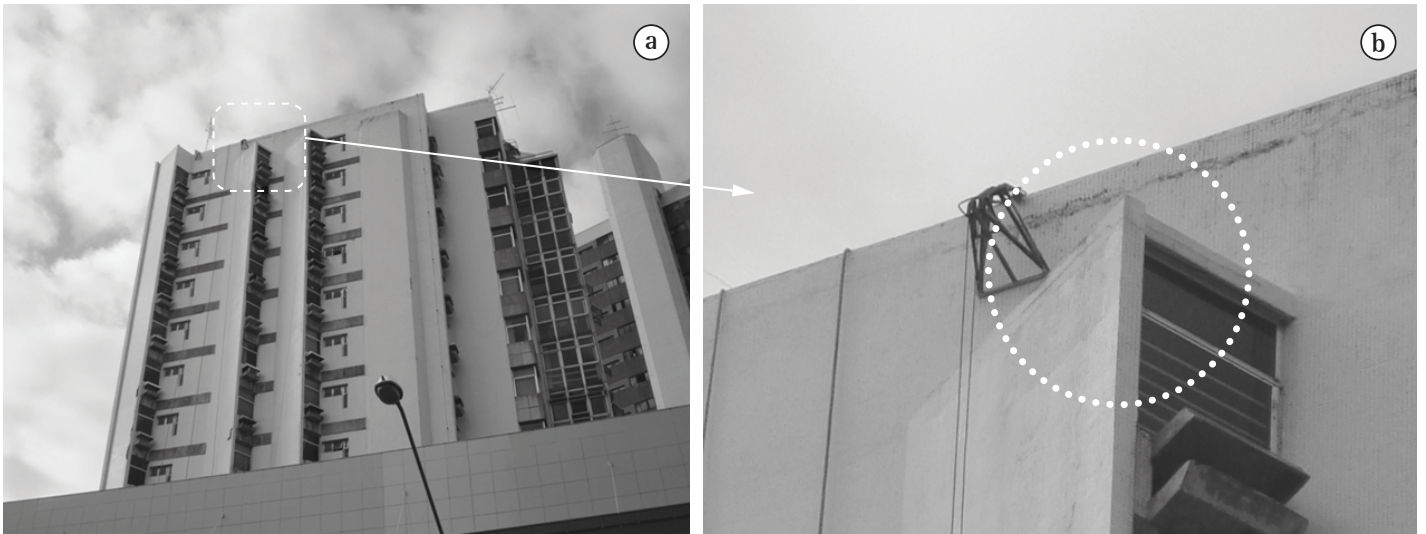

Figura 10. a) Fachada lateral direita - obra A. b) Detalhe da arquitetura da edificação que dificulta o acesso - obra A. Fonte: pesquisa de campo. 


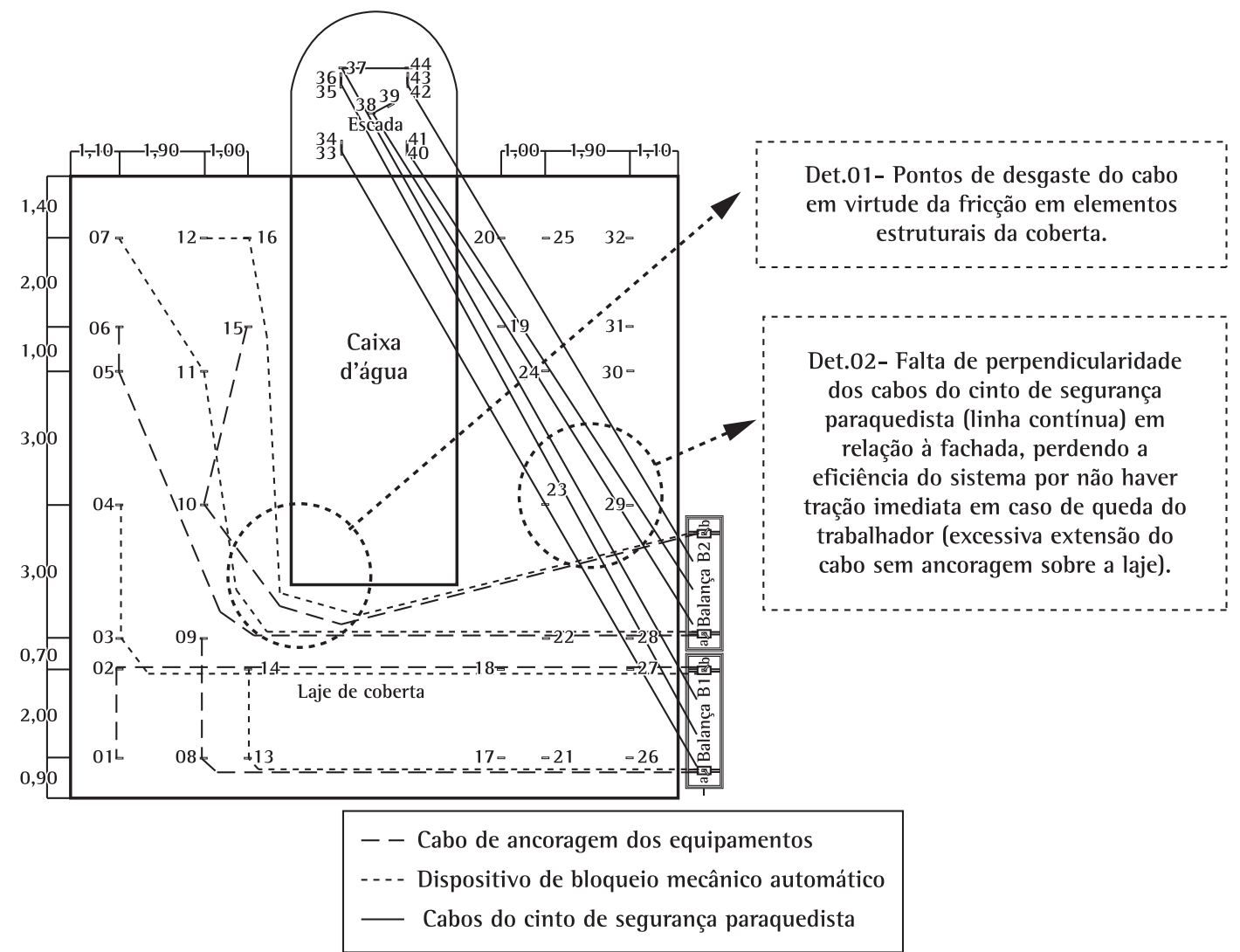

Figura 11. Falhas do projeto arquitetônico que dificultam a instalação e ancoragem da balança e cabos de segurança - obra D. Fonte: pesquisa de campo.

1. Alguns pontos de ancoragem (grampos de ferro $12,5 \mathrm{~mm}$ ) estavam em processo de corrosão avançado, com suas características de resistência comprometidas, sendo, portanto, sua utilização descartada;

2. 0 número de pontos de ancoragem era bastante limitado, havendo a necessidade de alguns cabos serem fixados em ancoragem distante da área de trabalho;

3. Em função das grandes extensões de cabos sobre a laje da coberta, observou-se o entrelaçamento deles e identificaram-se pontos de fragilidade, tendo em vista o desgaste de cabos em virtude da fricção em elementos estruturais da coberta (detalhe 1 da Figura 11);

4. Falta de perpendicularidade dos cabos fixados em relação à fachada (cabo do cinto de segurança paraquedista), ocasionando perda da eficiência do sistema em caso de queda do trabalhador. Nesse caso não haverá tração imediata do cabo devido à sua grande extensão sobre a laje, sem ancoragem intermediária (detalhe 2 da Figura 11).

Os resultados da pesquisa de campo demonstraram, além da falta de acessórios de ancoragem, dificuldades de execução em função de detalhes de arquitetura. Foram detectados problemas básicos de segurança com relação à montagem e fixação das balanças e cadeiras, responsabilidade esta da empresa de manutenção.

Na obra F, a empresa construtora fez a instalação de uma cadeira suspensa na edificação para instalar tubulação de recalque da água para a caixa d'água superior. A sustentação da cadeira suspensa foi feita com corda que apresentava filamentos danificados e a cadeira não dispunha de dispositivo de descida com dupla trava de segurança, além do que foi utilizado um único cabo para fixação da cadeira e do cinto de segurança, infringindo recomendações da NR18, detalhes já comentados anteriormente no item 4.2.2 deste artigo. A sustentação da cadeira suspensa feita com corda de filamentos danificados e sem dispositivo de descida com dupla trava de segurança desrespeitam a alínea b do item 18.15.51 da NR18. 0 cinto de segurança tipo paraquedista, além de não ter travaquedas, estava ligado ao único cabo de sustentação do equipamento, com a agravante de a cadeira suspensa ser de fabricação artesanal (Figura 12). 
Na obra E, os andaimes suspensos utilizados tinham apenas um guincho de sustentação por armação (Figura 13) e não havia cabo de segurança adicional de aço ligado a dispositivo de bloqueio mecânico automático instalado, como exigido no item 18.15.44 da NR18. Em caso de acidente com rompimento de um dos cabos de sustentação do equipamento, a estrutura do andaime perderia totalmente sua estabilidade, colocando em risco a vida do trabalhador.

\subsubsection{Manutenção em estruturas de concreto}

A obra $\mathrm{G}$ foi a única da pesquisa de campo em que as atividades de manutenção referiam-se à recuperação das estruturas de concreto armado. Em geral, suas atividades consistiram em fazer demolições do revestimento e depois o recobrimento do concreto armado, com a execução de proteções e reposições de seções de aço das armaduras e posterior recobrimento com concreto de alta resistência, atividades estas executadas em vigas e pilares.

Observou-se que os funcionários utilizavam EPI adequado à execução das atividades de demolição, como luvas de raspa e óculos de proteção, de acordo com NR6. Porém em algumas vigas que estavam sendo recuperadas, as armações positivas estavam totalmente expostas, situação que pode ser observada na Figura 14. Nesse caso é prudente a execução de escoramentos para garantia da estabilidade da edificação, e estes deveriam ter sido descritos e detalhados nos projetos de recuperação e nos de programas de segurança (PPRA ou PCMAT) da obra de manutenção.

Percebe-se que apesar desse problema não ser de segurança do trabalho, mas de um projeto inadequado de recuperação, ele afeta diretamente a segurança da estrutura, e por conseqüência, coloca em risco a segurança dos usuários e trabalhadores.

\section{Conclusões}

Na pesquisa de campo foram detectadas falhas de projeto arquitetônico nas oito edificações analisadas, as quais dificultavam diretamente as operações de manutenção. Dentre as principais, destacam-se: dificuldades de acesso à fachada devido a detalhes da arquitetura da edificação; inexistência ou quantitativo insuficiente de acessórios de ancoragem; instalações elétricas com difícil acessibilidade; e dificuldades de acesso às instalações hidráulicas.

Essas falhas de projeto podem indicar a falta ou ineficiência da análise das condições de segurança na concepção do projeto dessas edificações, haja vista terem sido detectadas nas edificações avaliadas

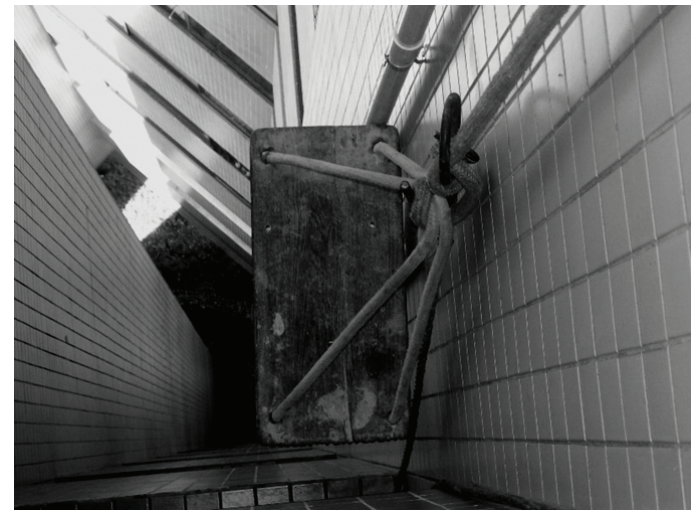

Figura 12. Cadeira suspensa inadequada, sem cabo independente para o cinto - obra F Fonte: pesquisa de campo.

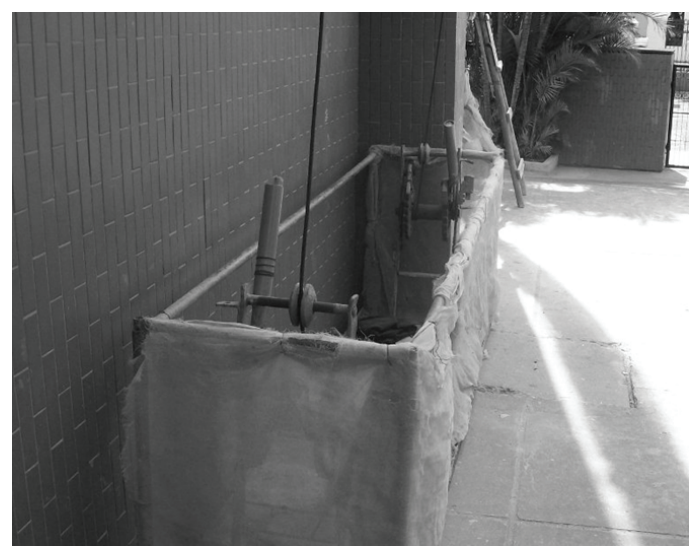

Figura 13. Andaime sem cabo de segurança do travaquedas - obra E. Fonte: pesquisa de campo.

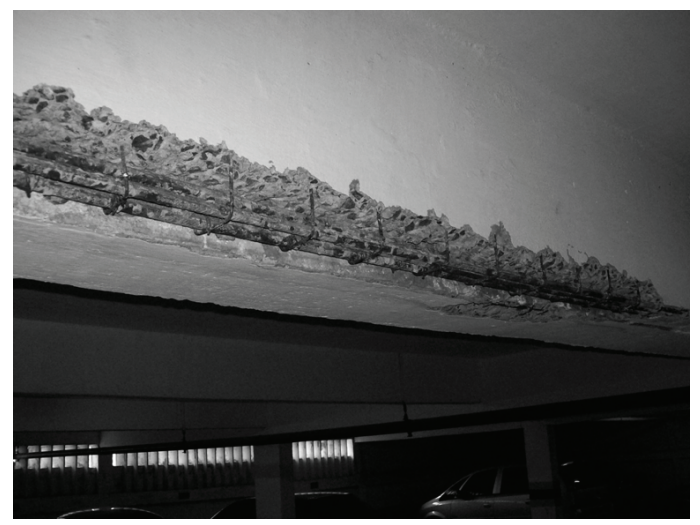

Figura 14. Demolição da estrutura de concreto armado sem escoramento adequado. Fonte: pesquisa de campo.

instalações físicas com inúmeras situações de risco para a fase de manutenção e que poderiam ser evitadas com a inclusão de dispositivos específicos de segurança na fase construtiva da obra, caso tivessem 
sido previstos no projeto. Verificou-se, porém, evolução e melhoria na qualidade dos projetos comparando-se as edificações mais antigas com as mais recentes. Foram evidentes as melhorias, principalmente nas instalações elétricas, sendo verificada adequação às normas específicas, principalmente a facilitação de acesso às instalações.

Com relação aos procedimentos de segurança das empresas de manutenção, percebe-se carência de profissional qualificado para implementar as ações de segurança, ocorrendo vários descumprimentos das leis de SST e aplicação de medidas de proteção ineficazes, dentre as quais podem ser citadas: inexistência de projeto dos sistemas de fixação e sustentação das estruturas de apoio dos andaimes suspensos; utilização de um mesmo ponto de ancoragem para fixação dos equipamentos e cabos para cinto de segurança; utilização de sistema de contrapeso com sólido granulado como ancoragem; instalação dos cabos de fixação permitindo a sua fricção com a platibanda ou detalhe construtivo da edificação, sem proteção do desgaste do cabo; instalação inadequada de andaimes, com afastamento excessivo em relação à fachada; e instalação improvisada de equipamentos.

Com relação aos procedimentos administrativos dos síndicos, ou das administradoras de condomínio, detectaram-se falhas no processo de contratação e de fiscalização das empresas de manutenção. Percebeu-se que o critério utilizado pela maioria dos condomínios foi o de menor preço, não sendo levada como premissa a experiência profissional da empresa ou qualificação do quadro técnico. Em contrapartida, em uma das obras visitadas verificou-se que foi adotado um processo criterioso de escolha da empresa, o que influenciou bastante na qualidade da obra e na eficácia das medidas de segurança implementadas.

Nesse caso, conclui-se que o investimento na fase de planejamento da obra de manutenção é uma importante medida tanto para a garantia da qualidade da obra quanto para a prevenção dos riscos de acidente do trabalho. Recomenda-se, portanto, que o condomínio contrate uma empresa especializada para organizar um processo licitatório, com descrição das especificações técnicas, além dos documentos mínimos exigíveis para a classificação das empresas concorrentes, destacando-se a exigência de apresentação do projeto de montagem e instalação das balanças, quando houver uso delas.

Visualizou-se, ainda, a necessidade de desenvolver futuros estudos para estabelecer diretrizes de segurança para o desenvolvimento dos projetos de edificações, visto que foram detectadas falhas nas edificações que dificultaram a garantia da segurança do trabalhador nas operações de manutenção.

\section{Referências}

ALMEIDA FILHO, R. P. et al. Caracterização dos sistemas de proteção das instalações elétricas nos canteiros de obras do Nordeste Brasileiro. In: CONGRESSO INTERNACIONAL DE SEGURANÇA, HIGIENE E SAÚDE DO TRABALHO, 2007, Porto. Anais.... Porto, 2007.

ASSOCIAÇÃO BRASILEIRA DE NORMAS TÉCNICAS - ABNT. NBR 5674: Manutenção de edificações - Procedimentos. Rio de Janeiro: ABNT, 1999.

ASSOCIAÇÃO BRASILEIRA DE NORMAS TÉCNICAS - ABNT. NBR 14.787: Espaço Confinado - Prevenção de acidentes, procedimentos e medidas de proteção. São Paulo: ABNT, 2001

ASSOCIAÇÃO BRASILEIRA DE NORMAS TÉCNICAS - ABNT. NBR 5410: Instalações elétricas de baixa tensão. São Paulo: ABNT, 2004

BARKOKÉBAS JUNIOR, B. et al. Diagnóstico de Segurança e Saúde no Trabalho em Empresa de Construção Civil no Estado de Pernambuco. In: CONGRESSO NACIONAL DE SEGURANÇA E MEDICINA DO TRABALHO, 13., 2004, São Paulo. Anais... São Paulo, 2004.

BARKOKEBAS JÚNIOR, B. et al. Indicadores de segurança do trabalho para direcionamento do sistema de gestão de segurança e saúde no trabalho. In: ENCONTRO NACIONAL DE ENGENHARIA DE PRODUÇÃO - ENEGEP, 26., 2006, Fortaleza. Anais... AEPRO, 2006.

BEZERRA, J. E. A.; TUBINO, D. F. A manutenção de condomínios em edifícios, TPM, terceirização e o JIT/ TQC. In: ENCONTRO NACIONAL DE ENGENHARIA DE PRODUÇÃO - ENEGEP, 2000, São Paulo. Anais... AEPRO, 2000.

BRASIL. Ministério do Trabalho e Emprego. Normas Regulamentadoras de Segurança e Medicina do Trabalho. Disponível em: <http//www.mte.gov.br>. Acesso em: 2 abr. 2011.

COOKE, T. et al. The development and evaluation of a decision support tool for health and safety in construction design. Engineering, Construction and Architectural Management, v. 15, n. 4, p. 336-351, 2008. http:// dx.doi.org/10.1108/09699980810886847

EDWARDS, D. J.; HOLT, G. D.; HARRIS, F. C. Predictive maintenance techniques and their relevance to construction plant. Journal of Quality in Maintenance Engineering, v. 4, n. 1, p. 25-37, 1998. http://dx.doi. org/10.1108/13552519810369057

GOMIDE, T. L. F. Técnicas de inspeção e manutenção predial. São Paulo: Pini, 2006.

HOLMES, S. M. M. Acidentes do trabalho fatais registrados pelo sistema federal de inspeção do trabalho em Pernambuco, no periodo de outubro de 2001 a dezembro de 2006. 2007. 159 f. Dissertação (Mestrado)-Universidade Federal de Pernambuco, Recife, 2007.

INTERNATIONAL LABOUR ORGANIZATION - ILO. Construction. Disponível em: <http://www.oit.org/ public/english/dialogue/sector/sectors/constr.htm>. Acesso em: 18 ago 2004.

KOHLMAN RABBANI, E. R. et al. Gerenciamento dos sistemas de proteção das instalações elétricas nos canteiros de obras da região metropolitana do recife RMR. In: ENCONTRO NACIONAL DE ENGENHARIA DE PRODUÇÃO - ENEGEP, 2007, Foz do lguaçu. Anais... AEPRO, 2007.

KOHLMAN RABBANI, E. R. et al. Análise dos sistemas de proteção e das instalações elétricas nas 
residências de Pernambuco. In: ENCONTRO NACIONAL DE TECNOLOGIA DO AMBIENTE CONSTRUIDDO - ENTAC, 12., 2008, Fortaleza. Anais... Fortaleza, 2008a.

KOHLMAN RABBANI, E. R. et al. Characterization of grounding systems for temporary electrical installations at high-rise construction - Study case in Recife / Brasil. In: INTERNATIONAL CONFERENCE ON OCCUPATIONAL RISK PREVENTION, 6., 2008, Galicia, Spain. Proceedings.... Galicia: Pedro R. Mondelo, 2008b.

LAGO, E. M. G. et al. Medidas de segurança relativas à impermeabilização em espaço confinado: estudo de caso em reservatório de água. In: SIMPÓSIO DE ENGENHARIA DE PRODUÇÃO - SIMPEP, 15., 2008, Bauru. Anais.... Bauru, 2008.

MARCELLI, M. Sinistros na construção civil: causas e soluções. São Paulo. Editora Pini, 2007.

MARTINS, M. S. Diretrizes para elaboração de medidas de prevenção contra quedas de altura em edificações. 2004. 182 f. Dissertação (Mestrado em Construcão Civil)-Universidade Federal de São Carlos, São Carlos, 2004.

MELHADO, S. B. et al. (Coords.). Coordenação de projetos de edificações. São Paulo: Editora O Nome da Rosa, 2005.

MÉLO FILHO, E. C.; KOHLMAN RABBANI, E. R.; BARKOKÉBAS JUNIOR, B. Propostas de medidas de proteção coletiva para construção de edifícios em estrutura metálica. In: ENCONTRO NACIONAL DE TECNOLOGIA DO AMBIENTE CONSTRUIDO - ENTAC,12., 2008, Fortaleza. Anais... Fortaleza, 2008. CD-ROM.

MÉlO FILHO, E. C. Adequação dos manuais de operação, uso e manutenção das edificações às normas de segurança e saúde do trabalho. 2009. 168 f. Dissertação (Mestrado)-Universidade de Pernambuco, Recife, 2009.

NARAYAN, V. The raison d'être of maintenance. Journal of Quality in Maintenance Engineering, v. 4, n. 1, p. 3850, 1998.http://dx.doi.org/10.1108/13552519810369066

PANPALON, G.; LENCI FILHO, R.; VICENTE, L. F. Prevenção de acidentes do trabalho em serviços de manutenção em fachadas. São Paulo. Disponível em: <http:// www.sintracon.org.br/manual.html>. Acesso em: 6 set. 2008.
RWAMAMARA, R. et al. Using visualization technologies for design and planning of a healthy construction workplace. Construction Innovation: Information, Process, Management, v. 10, n. 3, p. 248-266, 2010.

SPIELHOLZ, P.; CHAVEZ, M. Reducing injury risk factors through building specifications. In: INTERNATIONAL ASSOCIATION FOR THE EVALUATIO - IEA CONGRESS, 2006, Amsterdam. Proceedings... Amsterdam: Elsevier, 2006.

SINDICATO DA INDÚSTRIA DA CONSTRUÇÃO CIVIL DO ESTADO DE PERNAMBUCO - SINDUSCON/ PE. Campanha de Prevenção de Acidentes do Trabalho na Indústria da Construção Civil no Estado de Pernambuco - Relatório 2005-2006. Recife: SINDUSCON/PE, 2007. 133 p.

SOUZA, R. Metodologia para desenvolvimento e implantação de sistema de gestão da qualidade em empresas construtoras de pequeno e médio porte. 1997. Tese (Doutorado)-Escola Politécnica, Universidade de São Paulo, São Paulo, 1997.

SOUZA, A. L. R.; MELHADO, S. B. Preparação da execução de obras - PEO. São Paulo: 0 Nome da Rosa, 2003. 144 p.

VIANA, M. J. et al. (Coords.). RTP 05 - Recomendação técnica de procedimentos: Instalações elétricas temporárias em canteiros de obras. São Paulo: Fundacentro, 2007. 44 p.

XENOS, H. G. D. Gerenciando a manutenção produtiva. Belo Horizonte, 1998. $302 \mathrm{p}$

\section{Agradecimentos}

Este artigo foi finalizado durante o trabalho de pós-doutorado da autora Emilia Rahnemay Kohlman Rabbani, financiado pela CAPES Processo No. 0770-11-6 e Universidade de Pernambuco (UPE) e com o apoio do Programa de Pós-graduação em Engenharia Civil da UPE; da Universidade do Minho, Portugal, especialmente dos professores Dr. Said Jalali e Dr. Pedro Arezes; e do Departamento de Engenharia Civil e Ambiental do Technion - Israel Institute of Technology, em especial do prof. Dr. Aviad Shapira.

\title{
Occupational safety evaluation at high-rise building maintenance worksites
}

\begin{abstract}
The importance of building maintenance has grown in the construction sector, gradually overtaking the idea that the construction ends when the product is delivered. This study aimed to evaluate the condition of some high-rise building maintenance worksites in Recife, regarding their compliance with Occupational Safety and Health (OSH) regulations, and to identify key gaps in the building's design that can generate maintenance risks. The maintenance services of eight buildings, between October 2008 and February 2009, were analyzed according to a checklist based on the current Brazilian OSH standards and laws. Deficiencies in the buildings' architectural design, irregularities in safety procedures, and lack of knowledge by managers responsible for contracting and monitoring maintenance companies were observed. It was found that the planning and design of a building are vital to ensure workers' safety during the maintenance phase. The need to develop further studies to establish safety guidelines for building project development that anticipate maintenance and security needs for workers was verified.
\end{abstract}

Keywords

Building maintenance. Occupational safety and health (OSH). Construction. OSH management. Project management. 